\title{
Expansão dos cursos públicos de Serviço Social entre os anos de 2003 e 2016: desafios para a formação profissional
}

\author{
Larissa Dahmer Pereira \\ Universidade Federal Fluminense, Centro de Estudos Sociais \\ Aplicados, Escola de Serviço Social, Niterói, RJ, Brasil (UFF)
}

\begin{abstract}
Expansão dos cursos públicos de Serviço Social entre os anos de 2003 e 2016: desafios para a formação profissional

Resumo: O artigo analisa dados referentes aos cursos públicos de Serviço Social, criados entre 2003 e 2016, coletados no sistema eMEC. Os dados referem-se aos períodos e subperíodos de criação, categoria administrativa, organização acadêmica, região e localização geográfica. Como resultados, constata-se que o período em análise (2003 a 2016) criou mais da metade dos cursos públicos de Serviço Social, com significativo impacto para a formação na área pública. Contudo, no mesmo período, o setor privado também cresceu expressivamente, com forte mercantilização do ensino superior brasileiro e o uso significativo da modalidade de Ensino a Distância (EaD) como estratégia de expansão lucrativa. Ao mesmo tempo, observa-se, com base em diversos estudiosos do campo da Educação, uma expansão precarizada do setor público. Assim, indica-se a necessidade de pesquisas que conheçam a formação em tais cursos, problematizando seus limites e potencialidades, no intuito de fortalecer a formação pública, de qualidade, universal, gratuita e laica. Palavras-chave: Expansão do ensino superior. Formação profissional. Serviço Social.
\end{abstract}

Expansion of Public Colleges of Social Work from 2003 to 2016: Challenges for professional education Abstract: The article analyzes data referring to public colleges of social work created between 2003 and 2016, gathered from the e-MEC system of Brazil's Ministry of Education. The data refer to the periods and sub-periods of creation of the schools, their administrative categories, academic organization, region and geographic locations. The results indicate that in the period analyzed (2003 to 2016) more than half of the currently existing public schools of Social Work were created, with a significant impact on public education. The private sector also grew expressively in this period, indicating a strong commodification of Brazilian higher education and a significant use of the modality of distance education as a strategy to expand profits. Based on various studies in the field of education, an expansion of the precariousness of the public sector is also found. Thus, a need is indicated for studies that analyze education in these courses, problematizing their limits and potential, to strengthen universal, quality and secular public education that is free of charge.

Keywords: Expansion of higher education. Professional education. Social Work.

Recebido em 05.06.2017. Aprovado em 05.09.2017. Revisado em 01.12.2017.

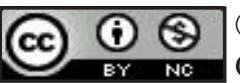

(C) $\mathrm{O}(\mathrm{s})$ Autor(es). 2018 Acesso Aberto Esta obra está licenciada sob os termos da Licença Creative Commons Atribuição-NãoComercial 4.0 Internacional (https://creativecommons.org/licenses/bync/4.0/deed.pt_BR), que permite copiar, distribuir e reproduzir em qualquer meio, bem como adaptar, transformar e criar a partir deste material, desde que para fins não comerciais, e que você forneça o devido crédito aos autores e a fonte, insira um link para a Licença Creative Commons e indique se mudanças foram feitas. 


\section{Introdução}

O trabalho objetiva traçar um perfil inicial dos cursos públicos de Serviço Social, criados entre os anos de 2003 a 2016, no contexto de expansão do ensino superior brasileiro, durante os governos Lula e Dilma Roussef.

Trata-se de um primeiro resultado de pesquisa sobre as condições formativas dos cursos públicos de Serviço Social no Brasil, desenvolvida no âmbito do Programa de Pós-Graduação em Serviço Social e Desenvolvimento Regional, da Universidade Federal Fluminense (PPGSSDR/UFF), sob a coordenação da autora ${ }^{1}$.

A pesquisa justifica-se em função do contexto de expansão significativa do ensino superior brasileiro, especialmente na primeira década e meia do século XXI, marcada pela predominância do setor privado mercantil, concentrada em conglomerados educacionais, e com uso intensivo do Ensino a Distância (EaD).

Ao analisarmos a curva de crescimento dos cursos públicos de Serviço Social criados nos diferentes períodos históricos, chamou-nos a atenção o quantitativo de cursos públicos criados durante os governos Lula e Dilma Roussef, o que nos instigou a iniciar a pesquisa em curso.

Assim, apresentamos o presente artigo, resultado do trabalho de coleta, organização e análise de dados extraídos do sistema e-MEC ${ }^{2}$, durante o primeiro semestre de $2017^{3}$. Analisamos os seguintes dados referentes aos cursos: (1) períodos e subperíodos de criação: com a divisão de períodos 1930/1945 (era Vargas); 1946/ 1963 (período liberal-democrático); 1964/1989 (ditadura civil-militar); 1990/1994 (governos Collor/Itamar); 1995/2002 (governos Cardoso); 2003/20164 (governos Lula e Dilma) e, subdivisão, 2003 a 2010 (governos Lula) e 2011 a 2016 (governos Dilma); (2) categoria administrativa: isto é, se criados em Instituição de Ensino Superior (IES) pública ou privada; (3) organização acadêmica: se criados em IES universitária ou não-universitária; (4) região geográfica do país na qual o curso foi criado; (5) e, por fim, localização geográfica: se o curso encontra-se na capital ou interior.

O texto apresenta inicialmente uma breve discussão - sem a pretensão de aprofundamento - quanto ao perfil de expansão do ensino superior brasileiro. Em seguida, expõe e analisa os dados coletados sobre os cursos públicos de Serviço Social criados no período 2003 a 2016 e, por fim, tece algumas considerações sobre o perfil de tais cursos e os desafios postos à profissão no sentido de fortalecer uma formação pública, de qualidade, universal, gratuita e laica ${ }^{5}$.

\section{Expansão do ensino superior brasileiro no período 1995-2015 em um contexto de contrarreforma do Estado e de incentivo estatal ao setor privado}

A análise da expansão dos cursos públicos de Serviço Social, no período localizado entre os anos de 2003 e 2016 (governos Lula e Dilma Roussef), exige-nos tecer, ainda que muito introdutoriamente, algumas características de tal processo: em um contexto de forte crescimento econômico, um discurso governamental pautado no neodesenvolvimentismo e a permanência do incentivo estatal ao setor privado no ensino superior, com a criação de programas como o Programa Universidade Para Todos (PROUNI) ${ }^{6}$, a expansão ocorreu majoritariamente com matrículas ofertadas por empresas de grande capital ${ }^{7}$ e que vêm se utilizando do $\mathrm{EaD}$ como estratégia de redução de custos e maximização de lucros.

Assim, ainda que o acesso ao ensino superior brasileiro faça parte das bandeiras e lutas históricas de setores da classe trabalhadora que estiveram, por décadas, alijados de tal direito, ${ }^{8}$ a forma e o conteúdo de tal expansão - com matrículas concentradas em IES com finalidades lucrativas - vêm respondendo mais a frações da burguesia, que precisam ampliar seus mercados, do que efetivamente à democratização do conhecimento, visto o perfil dessa expansão estar associado ao acesso via compra do serviço educacional, acompanhado da fragilidade do processo formativo no quesito qualidade acadêmica9.

Cabe-nos apresentar, para o adensamento das reflexões aqui realizadas, dados que expressam o predomínio do setor privado: em 1995, o setor público (IES - federais, estaduais e municipais) detinha 700.540 matrículas, enquanto o setor privado (empresarial e confessional/comunitário) respondia por 1.059.163 matrículas (INEP, 1995). Em duas décadas, o setor privado obteve um crescimento de 473,58\%, com 6.075 .152 matrículas, no ano de 2015, enquanto o setor público cresceu 178,66\% ao longo daqueles 20 anos (1995-2015), de 700.540 para 1.952.145 matrículas (INEP, 2015) ${ }^{10}$.

Outro dado importante é a forte tendência de crescimento de IES não-universitárias e sua (possível) predominância futura: em 1995, havia no país 631.771 matrículas em IES não-universitárias contra 1.127.932 matrículas em IES universitárias (INEP, 1995). Em 20 anos (1995-2015), as IES não-universitárias somam 3.754.142 matrículas, aproximando-se da participação das IES universitárias, que somam 4.273.155 matrículas. As matrículas em IES não-universitárias cresceram quase 500\%, enquanto as matrículas em IES universitárias obtiveram um ritmo de crescimento de menos de 300\% (INEP, 2015). 
O mesmo processo ocorre com as modalidades de ensino, de forma ainda mais impressionante: se em 2000, as matrículas em cursos presenciais somavam 2.694.245 e aquelas de cursos EaD totalizavam 1.682 (INEP, 2002) $)^{11}$, em 2015 as matrículas presenciais dobraram para 6.633 .545 (crescimento de 146,21\%, cursos presenciais), enquanto as de $\mathrm{EaD}$ passaram a totalizar o vertiginoso quantitativo de 1.393 .752 matrículas, com um crescimento da ordem de $82.762,78 \%$ (INEP, 2015). Isto é, ainda que matrículas em cursos de EaD não representem a maioria das matrículas de cursos de graduação no país, em termos absolutos, a tendência é de que, nos próximos anos - permanecendo o crescimento exponencial constatado -, a predominância seja de matrículas em cursos de graduação na modalidade de EaD.

Ainda que as matrículas estejam concentradas em IES

No âmbito do Serviço Social,

o período em análise criou

mais da metade dos cursos

públicos na área, desde o seu

nascedouro, nos anos 1930 ,

com forte impacto para a

formação na área pública.

Estes foram criados em um

contexto de expansão

precarizada via REUNI,

majoritariamente em IFES,

isto é, instituições

universitárias, com

obrigação legal de realização

do tripé ensino, pesquisa e

extensão e, no interior, nas

regiões sudeste e sul, mas

também nas demais regiões,

onde havia escassez e/ou

mesmo inexistência de cursos

públicos de Serviço Social. universitárias privadas e que tais IES devam, legalmente, realizar o tripé ensino, pesquisa e extensão, constata-se a concentração de docentes doutores e contratados em tempo integral nas IES públicas, especificamente, nas Instituições Federais de Ensino Superior (IFES). Ou seja, docentes com qualificação para pesquisa e com condições de trabalho para efetivação da mesma não estão majoritariamente nas IES privadas ${ }^{12}$, o que já indica aqui uma divisão de tarefas formativas entre as IES, com o ensino voltado para as IES privadas - que formam a maioria esmagadora dos profissionais do país para o mercado de trabalho - e, as IFES, que formam pesquisadores e futuros mestres/doutores, que provavelmente irão também alimentar o mercado educacional, vendendo sua força de trabalho a preço rebaixado para as IES privadas.

E fundamental, a nosso ver, apresentarmos os dados das duas últimas décadas, demonstrando o perfil de expansão do ensino superior brasileiro, concentrado no setor privado mercantil ${ }^{13}$, para que não percamos a perspectiva de totalidade. Isto é, a apresentação dos dados até aqui objetivou demonstrar o predomínio do setor privado e a forte tendência de crescimento das matrículas em IES nãouniversitárias e ofertadas por meio do $\mathrm{EaD}^{14}$. Ou seja, um ensino superior ofertado sem o tripé ensino, pesquisa e extensão, vide as condições do trabalho docente já brevemente assinaladas.

De forma ampliada, este é o perfil de expansão do ensino superior brasileiro. Contudo cabe-nos alertar para o crescimento de vagas - ainda que diminuto, relativamente ao crescimento do setor privado - no setor público, especialmente nas Instituições Federais de Ensino Superior (IFES), que por meio do Decreto $n^{\circ} 6.096$, de 24 de abril de 2007 (BRASIL, 2007), instituiu o Programa de Apoio a Planos de Reestruturação e Expansão das Universidades Federais (REUNI) e possibilitou o ingresso de mais estudantes, com menor renda familiar, nas IFES ${ }^{15}$. Conforme observam Mancebo, Vale e Martins (2015, p. 38), a expansão do setor público, localizada especialmente nos governos Lula (20032010), efetivamente incrementou as matrículas no setor público, mas limitada a um processo de certificação, sem efetivas condições de trabalho docente ${ }^{16}$.

Sem dúvida, o crescimento do setor público no período supracitado foi significativo, embora, ao compararmos com o crescimento do setor privado, percebamos a predominância deste último, conforme Sguissardi (2008, p. 996):

O modelo de expansão da educação superior no Brasil tem uma longa história, mas, para caracterizá-lo, basta verificar sua evolução nos últimos anos. A multiplicação dos campi das IFES, a criação recente de mais 12 universidades federais em diversos estados do Brasil, beneficiando importantes regiões metropo- 
litanas, mas especialmente do interior do país, e, certamente, o REUNI deverão ter importante impacto nos números referentes às instituições e matrículas do setor público federal. Mas, infelizmente, seu efeito sobre a participação percentual do setor público no total de IES e de matrículas será diminuto diante do muito mais expressivo crescimento do setor privado, especialmente representado pelo sub-setor particular ou privado/mercantil.

É crucial reconhecer que a expansão realizada por meio do REUNI foi, ainda que muito parcialmente, uma resposta dos governos Lula/Dilma a demandas históricas de movimentos sociais que exigiam o acesso à Universidade Pública, a uma Política de Assistência Estudantil que garantisse a permanência, à interiorização, a vagas em cursos noturnos para discentes trabalhadores, às cotas para estudantes de escolas públicas e cotas raciais, dentre outros. Contudo, tal expansão veio acompanhada de forte precarização, com recursos insuficientes, porque se manteve o ajuste fiscal e a limitação de alocação direta de recursos nas IFES. ${ }^{17} \mathrm{~A}$ expansão majoritariamente, como vimos, ocorreu via setor privado, que por meio de isenções fiscais - beneficiado com programas governamentais como o PROUNI e o Fundo de Financiamento Estudantil (FIES) ${ }^{18}$ - pôde se expandir de forma veloz ${ }^{19}$.

$\mathrm{Na}$ área de Serviço Social, mais da metade dos cursos públicos atualmente existentes foi criada entre os anos de 2003 e 2016, o que é muito impactante para a profissão. Lembremos que o período da ditadura militar fora o que havia criado, até então o maior número de cursos públicos de Serviço Social no país, o que trouxe inclusive, dentre outros fatores, a possibilidade concreta de renovação profissional ${ }^{20}$.

Considerando a crítica até aqui realizada, ainda que de forma muito introdutória ${ }^{21}$, quanto à expansão mercantilizada do ensino superior brasileiro e, ainda, à expansão precarizada do setor público, no período em análise, objetivamos apresentar um mapeamento dos cursos públicos de Serviço Social, criados entre os anos de 2003 e 2016.

\section{Mapeamento da expansão dos cursos públicos de Serviço Social no período 2003-2016}

O período localizado entre os anos 2003, primeiro ano do governo Lula, e 2016, último ano do governo Dilma, ${ }^{22}$ criou a maior quantidade de cursos públicos de Serviço Social desde o seu surgimento, na década de $1930^{23}$. Conforme visualizamos a seguir, de acordo com a data de funcionamento, o período 2003-2016 criou mais de metade dos cursos públicos (53\%) cadastrados atualmente no sistema e-MEC ${ }^{24}$ : do total de 64 (sessenta e quatro) cursos públicos de Serviço Social, 34 (trinta e quatro) foram criados no período entre 2003 e 2016, superando os anos da ditadura civil-militar, que até então era a maior responsável pela criação do maior número de cursos públicos de Serviço Social (12 - doze - cursos entre 1964 e 1989) no país, seguido do período liberal-democrático (1946/1963, 8 - oito - cursos).

\section{Gráfico 1 - Cursos públicos de Serviço Social criados por período histórico}

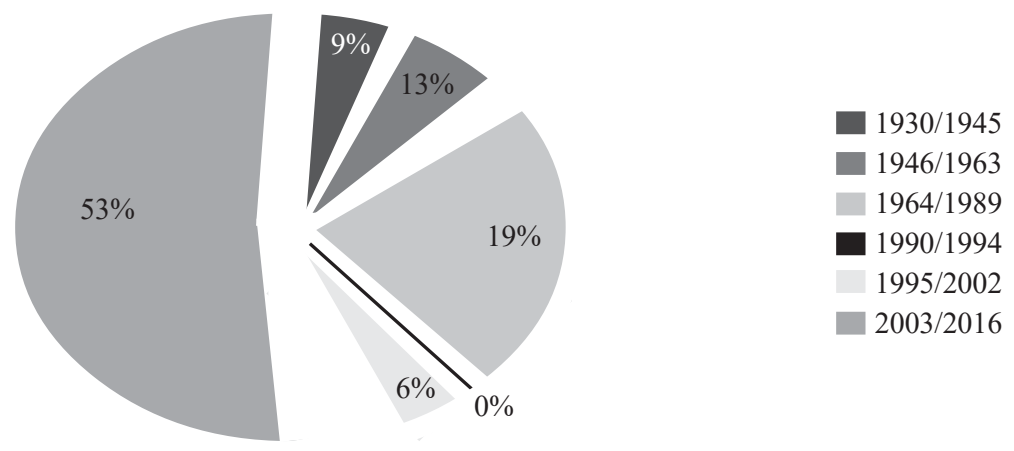

Fonte: Dados coletados do sistema E-MEC, em maio de 2017. Elaboração própria.

No gráfico 2, constatamos que, do total de 34 (trinta e quatro) cursos criados entre 2003 e 2016, parte expressiva (23, vinte e três, cursos $=68 \%$ ) foi criada em Instituições Federais de Ensino Superior (IFES), o que se relaciona claramente com o projeto de expansão das IFES - REUNI - por parte do governo federal. 
As IES estaduais representaram 26\% (09, nove) dos cursos de Serviço Social criados no período. Enquanto as municipais somaram 2 (dois) cursos, representando $6 \%$ dos cursos públicos de Serviço Social criados no período em análise (gráfico 2).

Gráfico 2 - Cursos públicos de Serviço Social por categoria administrativa - 2003 a 2016
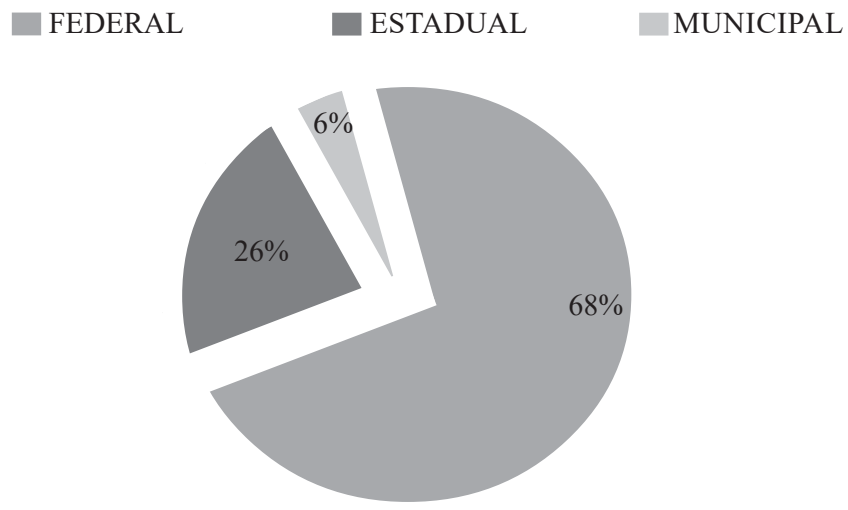

Fonte: Dados coletados do sistema E-MEC, em maio de 2017. Elaboração própria.

Quando analisamos os subperíodos em que tais cursos foram criados (gráfico 3), dentro do período mais amplo dos governos Lula (2003-2010) e Dilma (2011-2016), apreende-se que a criação dos cursos públicos de Serviço Social ficou concentrada nos governos Lula, com a criação de 29 (vinte e nove) cursos, representando $85,3 \%$ dos cursos públicos criados no período 2003/2016.

Se no período da ditadura civil-militar (1964/1989) foram criados 12 (doze) cursos públicos de Serviço Social, somente no período Lula, isto é, em 8 (oito) anos (2003-2010) tivemos a criação de mais do que o dobro de cursos, o que é extremamente significativo para a profissão e exige o acompanhamento de como tais cursos estão desenvolvendo o processo formativo de novos assistentes sociais ${ }^{25}$.

\section{Gráfico 3 - Cursos públicos de Serviço Social criados entre os anos 2003/2010 e 2011/2016}

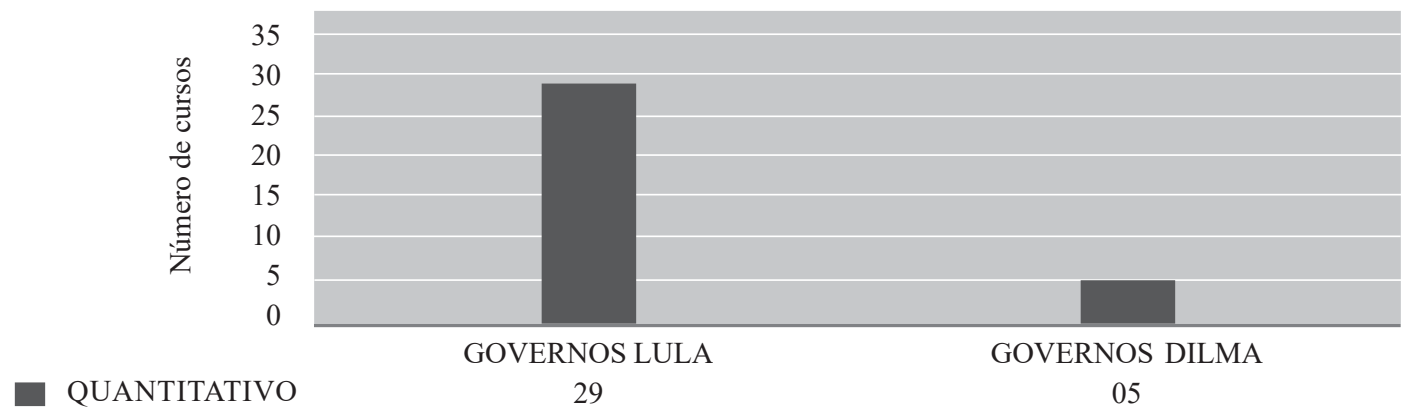

Fonte: Dados coletados do sistema E-MEC, em maio de 2017. Elaboração própria.

Quanto à organização acadêmica (gráfico 4), a maior parte ( $91 \%$ - 31, trinta e um) dos cursos públicos de Serviço Social, criados no período 2003/2016, encontra-se inserida em IES universitárias. Dos 3 (três) cursos não-universitários criados no período, 2 (dois) assim o foram em IES públicas municipais e 1 (um) encontra-se inserido em Instituto Federal de Educação, Ciência e Tecnologia. 
Gráfico 4 - Cursos públicos de Serviço Social por organização acadêmica - 2003 a 2016

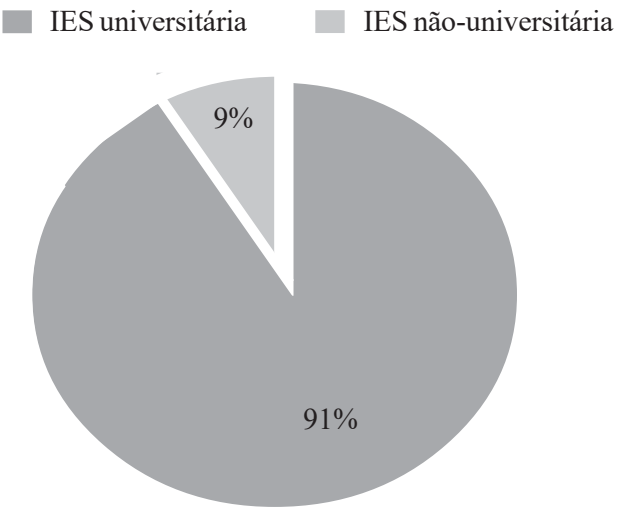

Fonte: Dados coletados do sistema E-MEC, em maio de 2017. Elaboração própria.

O gráfico 5 nos informa que a concentração dos cursos permaneceu na região sudeste (44\%), seguida da sul (20\%), perfazendo o total de $64 \%$ de cursos públicos criados nas regiões mais ricas e populosas do país. O nordeste também contou com a criação expressiva de 6 (seis) novos cursos públicos ${ }^{26}$, enquanto o norte teve 5 (cinco) novos cursos públicos ${ }^{27}$ criados no período. A região centro-oeste teve 1 (um) novo curso de Serviço Social criado em uma IFES, ${ }^{28}$ em Goiás, somando-se aos 2 (dois) cursos públicos existentes até então, no Distrito Federal e Mato Grosso.

Gráfico 5 - Cursos públicos de Serviço Social por região geográfica - 2003 a 2016

SUL

SUDESTE

- CENTRO-OESTE

NORDESTE

NORTE

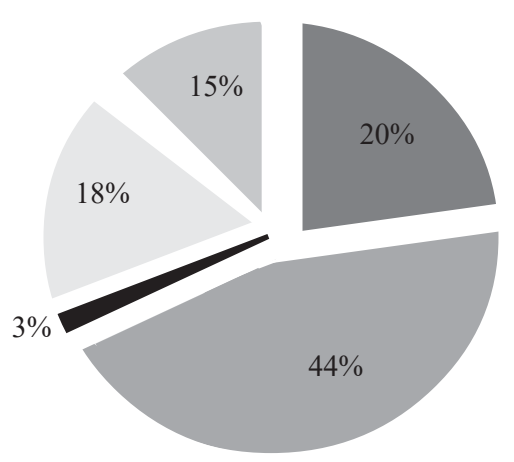

Fonte: Dados coletados do sistema E-MEC, em maio de 2017. Elaboração própria.

Ao analisarmos a distribuição dos cursos por região, é interessante observar que, na região sudeste que já contava com muitos cursos públicos, especialmente concentrados no estado do Rio de Janeiro ${ }^{29}-$, a criação dos cursos foi especialmente significativa nos estados de Minas Gerais e São Paulo. 
São Paulo, que contava somente com um curso público de Serviço Social, fundado na década de 1970, passou a contar com mais 2 (dois) cursos: 1 (um), em Santos, e outro em Bragança Paulista. ${ }^{30}$ Já em Minas Gerais, o estado teve, durante mais de meio século, somente 1 (um) curso público, inserido em IFES. Em 2002, passou a contar com 1 (um) curso público em IES estadual e, no período seguinte (2003/2016), obteve mais 5 (cinco) cursos em IFES e 5 (cinco) cursos em IES estadual ${ }^{31}$.

$\mathrm{Na}$ região sul, merece destaque e atenção a abertura de 7 (sete) cursos públicos na região sul, ${ }^{32}$ onde existiam até então somente 1 (um) curso em IFES, em Santa Catarina, e 6 (seis) cursos inseridos em IES estaduais.

No nordeste, destaca-se a criação especialmente dos cursos criados na Bahia, estado nordestino que não tinha nenhum curso público de Serviço Social ${ }^{33}$.

No gráfico 6, visualizamos que os cursos foram criados majoritariamente no interior, correspondendo a $82 \%$ (28, vinte e oito) do total criado em IES públicas no período 2003/2016. Na capital, foram criados $18 \%$ (6, seis) dos cursos públicos.

Dos 6 (seis) cursos criados em capitais, 5 (cinco) o foram em capitais onde inexistia curso público de Serviço Social (Boa Vista/Roraima; Palmas/Tocantins; Porto Alegre/Rio Grande do Sul; Goiás/Goiânia; Salvador/Bahia), com anterior exclusividade das IES católicas e/ou privadas.

\section{Gráfico 6 - Cursos públicos de Serviço Social por localização geográfica - 2003 a 2016}

$$
\text { Interior } \quad \text { Capital }
$$

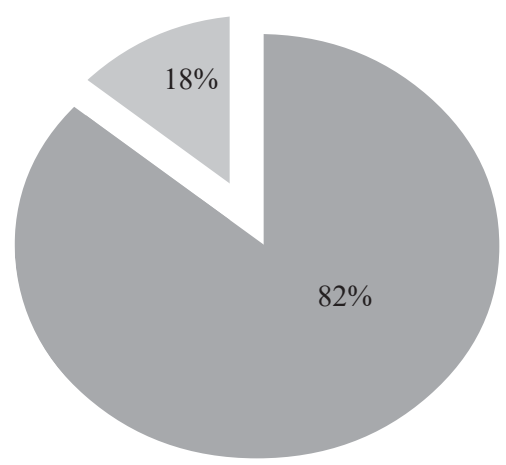

Fonte: Dados coletados do sistema E-MEC, em maio de 2017. Elaboração própria.

\section{Considerações finais}

Após breve apresentação dos dados e com os limites de um artigo, constata-se, em acordo com autores citados no texto, que a expansão do ensino superior brasileiro vem sendo marcada por intenso processo de mercantilização e crescimento exponencial de matrículas em cursos de EaD.

No âmbito do Serviço Social, o período em análise criou mais da metade dos cursos públicos na área, desde o seu nascedouro, nos anos 1930, com forte impacto para a formação na área pública. Estes foram criados em um contexto de expansão precarizada via REUNI, majoritariamente em IFES, isto é, instituições universitárias, com obrigação legal de realização do tripé ensino, pesquisa e extensão e, no interior, nas regiões sudeste e sul, mas também nas demais regiões, onde havia escassez e/ou mesmo inexistência de cursos públicos de Serviço Social.

Buscamos contribuir com um mapeamento nacional e ainda introdutório, mas reiteramos a necessidade do desenvolvimento de pesquisas que conheçam e acompanhem a formação em tais cursos, de forma mais qualitativa, indicando seus limites frente à política educacional em curso e objetivando qualificar o processo formativo, com a perspectiva de afirmação e luta pelo direito à educação superior pública, de qualidade, laica, universal e gratuita. 


\section{Referências}

BRASIL. Decreto $n^{\circ}$ 6.096, de 24 de abril de 2007. Institui o Programa de Apoio a Planos de Reestruturação e Expansão das Universidades Federais - REUNI. Diário Oficial da União, Brasília, DF, 25 abr. 2007b. Disponível em: <http://www.planalto.gov.br/ccivil_03/ _ato2007-2010/2007/decreto/d6096.htm>. Acesso em: 8 maio 2017.

. Lei $\mathrm{n}^{\circ}$ 10.260, de 12 de julho de 2001. Dispõe sobre o Fundo de Financiamento ao estudante do Ensino Superior e dá outras providências. Diário Oficial da União, Brasília, DF, 13 jul. 2001. Disponível em: <http://www.planalto.gov.br/ccivil_03/leis/LEIS_2001/ L10260.htm>. Acesso em: 4 abr. 2016.

. Lei n ${ }^{\circ} 11.096$, de 13 de janeiro de 2005. Institui o Programa Universidade para Todos - PROUNI, regula a atuação de entidades beneficentes de assistência social no ensino superior; altera a Lei n ${ }^{\circ} 10.891$, de 9 de julho de 2004, e dá outras providências. Diário Oficial da União, Brasília, DF, 14 jan. 2005. Disponível em: <http://www.planalto.gov.br/ccivil_03/_ato2004-2006/2005/lei/111096.htm>. Acesso em: 14 fev. 2015.

. Ministério da Educação. Cadastro e-MEC de Instituições e Cursos de Educação Superior. Brasília, DF: MEC, 2017. Disponível em: <http://emec.mec.gov.br/>. Acesso em: 13 nov. 2017.

Portaria Normativa $\mathrm{n}^{\circ}$ 40, de 12 de dezembro de 2007. Institui o e-MEC, sistema eletrônico de fluxo de trabalho e gerenciamento de informações relativas aos processos de regulação da educação superior no sistema federal de educação. Diário Oficial da União, Brasília, DF, 13 dez. 2007a. Disponível em: <http://download.inep.gov.br/download/condicoes_ensino/2007/Portaria_n40.pdf>. Acesso em: 8 maio 2017.

CONSELHO NACIONAL DE EDUCAÇÃO. Desenvolvimento, aprimoramento e consolidação de uma Educação nacional de qualidade. Projeto CNE/UNESCO 914BRZ11142.3. Brasília, DF: MEC, 2014. Disponível em: <http://portal.mec.gov.br/ index.php?option=com_docman\&view=download\&alias=15878-centros-universitarios-produto-1-pdf\&category_slug=junho-2014pdf\&Itemid=30192>. Acesso em: 2 maio 2017.

CORAL, M. As contradições e tendências do processo de expansão e interiorização da Universidade Federal de Alagoas e seus rebatimentos no Curso de Serviço Social de Palmeira dos Índios. 2016. Tese (Doutorado em Serviço Social) - Universidade Federal de Pernambuco, Recife, 2016.

FÉRRIZ, A. F. P. et al. Os impactos da expansão do ensino superior na vida dos docentes e discentes do Curso de Serviço Social da Universidade Federal da Bahia. In: ENCONTRO NACIONAL DE PESQUISADORES EM SERVIÇO SOCIAL, 15., Ribeirão Preto, SP. Anais... Brasília, DF: ABEPSS, 2017. No prelo.

GONÇALVES, C. A. O Programa REUNI: significados e ressonâncias da implantação do curso de Serviço Social da UFG/CCG 2008/ 2012. 2013. Tese (Doutorado em Serviço Social) - Pontifícia Universidade Católica de São Paulo, São Paulo, 2013.

IBGE. Síntese de indicadores sociais: uma análise das condições de vida da população brasileira - 2015. Rio de Janeiro: IBGE, 2015 .

INEP. Sinopse Estatística da Educação Superior 1995. Brasília, DF: INEP, 1995. Disponível em: <http://portal.inep.gov.br/web/guest/ sinopses-estatisticas-da-educacao-superior>. Acesso em: 15 abr. 2017.

. Sinopse Estatística da Educação Superior 2000. Brasília, DF: INEP, 2002. Disponível em: <http://portal.inep.gov.br/web/ guest/sinopses-estatisticas-da-educacao-superior>. Acesso em: 15 abr. 2017.

. Sinopse Estatística da Educação Superior 2015. Brasília, DF: INEP, 2015. Disponível em: <http://portal.inep.gov.br/web/ guest/sinopses-estatisticas-da-educacao-superior>. Acesso em: 15 abr. 2017.

LIMA, K. R. de S. O Programa Reuni e os desafios para a formação profissional em Serviço Social. Revista Katálysis, Florianópolis, v. 16, n. 2, 258-267, 2013. Disponível em: <https://dx.doi.org/10.1590/S1414-49802013000200012>. Acesso em: 5 maio 2017.

MANCEBO, D.; VALE, A. A. do; MARTINS, T. B. Políticas de expansão da educação superior no Brasil 1995-2010. Revista Brasileira de Educação, v. 20, n. 60, p. 31-50, jan./mar. 2015. Disponível em: <http://www.scielo.br/pdf/rbedu/v20n60/1413-2478-rbedu-20-600031.pdf>. Acesso em: 3 maio 2017.

NEVES, L. M. W.; PRONKO, M. A. O mercado do conhecimento e o conhecimento para o mercado. Rio de Janeiro: Fundação Oswaldo Cruz; Escola Politécnica Joaquim Venâncio, 2008. Disponível em: <http://www.epsjv.fiocruz.br/sites/default/files/140.pdf $>$. Acesso em: 11 maio 2017.

NETTO, J. P. Ditadura e serviço social: uma análise do serviço social no Brasil pós-64. São Paulo: Cortez, 1996.

PEREIRA, L. D. Educação e Serviço Social: do confessionalismo ao empresariamento da formação profissional. São Paulo: Xamã, 2008. .; SOUZA, A. C. V. de. Mercantilização do ensino superior brasileiro e o uso do EaD como estratégia expansionista. In: COLÓQUIO INTERNACIONAL MARX E O MARXISMO, 1., 2017, Niterói. Anais... Niterói: UFF, 2017. Disponível em: <http:/ /www.niepmarx.blog.br/MM2017/anais2017/MC30/mc301.pdf>. Acesso em: 3 out. 2017.

;___. FERREIRA, A. T. dos S. Ensino superior mercantilizado e seus impactos para o perfil profissional de Serviço Social. In: MOTTA, V. C. da; PEREIRA, L. D. Educação e Serviço Social: subsídios para uma análise crítica. Rio de Janeiro: Lumen Juris, 2017. p. 187-210.

SGUISSARDI, V. Modelo de expansão da educação superior no Brasil: predomínio privado/mercantil e desafios para a regulação e a formação universitária. Revista Educação \& Sociedade, Campinas, v. 29, n. 105, p. 991-1022, set./dez. 2008. Disponível em: <http:// www.scielo.br/pdf/es/v29n105/v29n105a04.pdf>. Acesso em: 10 jul. 2013. 
VALE, A. A. do “As faculdades privadas não fazem pesquisa porque não querem jogar dinheiro fora”: a trajetória da Estácio de Sá da filantropia ao mercado financeiro. 2011. 446f. Tese (Doutorado em Políticas Públicas e Formação Humana) - Faculdade de Educação, Universidade do Estado do Rio de Janeiro, Rio de Janeiro, 2011. Disponível em: <http://www.ppfh.com.br/wp-content/uploads/2014/ 01/T_AAdoVale.pdf>. Acesso em: 29 maio 2017.

VILLAR, V. L. C. Formação em Serviço Social: a implantação do curso em universidades públicas federais do Rio Grande do Sul. 2015. Tese (Doutorado em Serviço Social) - Pontifícia Universidade Católica do Rio Grande do Sul, Porto Alegre, 2015.

VITORINO, B. de M. Reflexos da expansão do ensino superior na formação profissional do assistente social. 2016. Dissertação (Mestrado em Serviço Social) - Universidade Estadual Paulista Júlio de Mesquita Filho, Franca/SP, 2016.

\section{Notas}

1 Agradeço ao Departamento de Serviço Social da UFF, pela liberação nesse último ano para a realização de Pós-Doutorado. E, ao Programa de PósGraduação em Educação da Universidade Federal do Rio de Janeiro, onde concluí Pós-Doutorado em Educação, junto ao Coletivo de Estudos Marxismo e Educação (COLEMARX), sob a supervisão da professora Vânia Cardoso da Motta.

2 "Cadastro e-MEC de Instituições e Cursos de Educação Superior, base de dados oficial e única de informações relativas às Instituições de Educação Superior(IES) e cursos de graduação do Sistema Federal deEnsino. Os dados do Cadastro e-MEC devem guardar conformidade com os atos autorizativos das instituições e cursos de educação superior, editados com base nos processos regulatórios competentes. (BRASIL, 2007a). É facultado à IES pertencente ao Sistema Estadual de Ensino, regulada e supervisionada pelo respectivo Conselho Estadual de Educação, fazer parte do Cadastro e-MEC, entretanto, as informações relacionadas a elas são declaratórias e de responsabilidade exclusiva dessas instituições". (BRASIL, 2017).

3 O banco de dados do grupo de pesquisa da autora foi criado em $2010 \mathrm{e}$, para este trabalho, foi atualizado com base no sistema e-MEC, entre setembro de 2016 e maio de 2017, pelas discentes bolsistas de Iniciação Científica Caroline Dias (PIBIC/CNPq), Jamile Nunes (FAPERJ)e Luana Mozer (PROAES e PIBIC/CNPq), sendo revisados por esta última e pela orientadora das mesmas, autora deste artigo.

4 Para a análise da expansão dos cursos públicos de Serviço Social, consideramos os dados até o ano de 2016, último ano do governo Dilma, quando ainda foi criado 1 (um) curso público de Serviço Social.

5 Cabe destacar que este é um primeiro momento da pesquisa, de análise dos dados disponíveis no sistema e-MEC. Um segundo momento da pesquisa, em andamento, prevêo contato com as Coordenações de Curso de tais cursos, buscando conhecer de forma mais qualitativa as condições formativas e de trabalho docente.

6 Criado pelo Governo Federal em 2004 e institucionalizado pela Lei no 11.096, em 13 de janeiro de 2005 oferece isenção de tributos àquelas instituições que aderem ao Programa (BRASIL, 2005).

7 A pesquisa de Vale (2011) analisa de forma crítica tal processo de concentração.

8 Sem dúvida, a falta de acesso ao ensino superior no país - por parte da maior parte da classe trabalhadora-constitui-se como uma dívida histórica, decorrente do padrão dependente educacional e que se relaciona com a superexploração da força de trabalho e a baixa necessidade, por parte das empresas capitalistas, de uso de força de trabalho majoritariamente qualificada. Para a discussão sobre a formação para o trabalho complexo na ordem burguesa contemporânea, com uma análise da particularidade brasileira, cf. Neves e Pronko (2008).

9 O que se relaciona com a necessidade do setor privado ampliar lucros e aumentar a competitividade, com a redução de custos. Com tais objetivos e operando a educação com a lógica mercantil, a qualidade acadêmica se esvai, destituída da dimensão de pesquisa e forte intensificação do trabalho docente.

10 Em 2015, a Sinopse Estatística do Ensino Superior 2015 nos apresenta as matrículas, em cursos presenciais e a distância (INEP, 2015). Já em 1995, as matrículas são somente em cursos presenciais (INEP, 2015).

11 Na Sinopse Estatística do ano de 2000 (INEP, 2002) aparecem pela primeira vez as matrículas em EaD.

12 O processo de expansão desencadeado nos governos Lula, especialmente a partir do Decreto n ${ }^{\circ} 6.096$, de 24 de abril de 2007, que instituiu o Programa de Apoio a Planos de Reestruturação e Expansão das Universidades Federais (REUNI) (BRASIL, 2007b) - efetivamente possibilitou o ingresso de mais estudantes, com menor renda familiar, nas IFES. Cf. dados em Síntese de Indicadores Sociais 2015 (INSTITUTOBRASILEIRO DE GEOGRAFIAE ESTATÍSTICA, 2015). Contudo, frente aos limites orçamentários, decorrentes da manutenção do ajuste fiscal, a expansão ocorreu de forma precarizada.

13 Cf. análise de Sguissardi (2008), sobre a predominância do setor privado mercantil.

14 O documento resultante de consultoria realizada para o Conselho Nacional de Educação (CNE) e o Ministério da Educação (MEC) (CNE, 2014), aponta uma série de problemas relativos à expansão por meio do $\mathrm{EaD}$.

15 Cf. dados em Síntese de Indicadores Sociais 2015 (IBGE, 2015).

16 As greves nacionais docentes das IFES, nos anos de 2012 e 2015, merecem registro e revelam as contradições presentes no processo de expansão do ensino superior público, que ampliou efetivamente vagas discentes e docentes, especialmente no interior do país, mas frente a um limitado orçamento não ampliou os recursos de forma adequada e suficiente, gerando fortes insatisfações no corpo docente recém-ingresso e já portador do título de Doutorado, bem como, no corpo discente.

17 Não é nosso intuito neste trabalho aprofundar a análise sobre o REUNI de forma geral, visto que pretendemos apresentar um panorama do crescimento dos cursos públicos de Serviço Social no período. Cabe destacar, contudo, que a crítica central ao REUNI não se relaciona com a negação da entrada de novos segmentos da classe trabalhadora na Universidade Pública, mas à sua inserção precarizada. 
18 Destinado ao financiamento da graduação de nível superior de estudantes matriculados em instituições privadas, é um programa do Ministério da Educação, criado em 1999, ainda no governo FHC. Cf. BRASIL (2001).

19 Cf. Mancebo, Vale e Martins (2015).

20 Cf. Netto (1996) e Pereira (2008).

21 Parte da fundamentação desse item, sobre a expansão do ensino superior brasileiro, encontra-se publicada de forma mais detalhada em Pereira e Souza (2017).

22 A presidente Dilma Roussef (Partido dos Trabalhadores - PT) sofreu impeachment, em 31 de agosto de 2016, aprovado pelo Senado e, anteriormente, pela Câmara dos Deputados. Foi um processo extremamente tenso e de muitas controvérsias. Assumiu em seu lugar o vicepresidente Michel Temer (Partido do Movimento Democrático Brasileiro - PMDB), ex-aliado do PT nas eleições presidenciais e cujo partido votou majoritariamente a favor do impeachment da presidente Dilma. Embora não seja este o objeto de nosso trabalho, énecessário demarcar que, ainda que com críticas radicais à forma como o PT conduziu diversas políticas e alianças, avaliamos que o impeachment significou um duro golpe à democracia no país: um golpe proveniente do Judiciário e do Legislativo, que objetivou manter no poder representantes de setores do grande capital que não aceitaram as ações dos governos Lula e Dilma de mínima democratização (enviesada, ao nosso ver) da sociedade brasileira. Para nossas elites reacionárias, os governos Lula e Dilma realizaram parte do que precisava ser feito. Seria preciso a entrada de um governante como Michel Temer para finalizar as contrarreformas que os governos Lula e Dilma não levaram a cabo plenamente, como as contrarreformas da Previdência (em sua plenitude neoliberal) e a Trabalhista.

23 Embora tenha sido o período em que mais foram criados cursos públicos de Serviço Social, este também foi marcado pelo crescimento significativo do setor privado, mas especialmente pelo surgimento dos cursos privados de Serviço Social na modalidade de EaD. Para uma análise sobre a formação no período, com dados mais amplos do processo de mercantilização, cf. Pereira, Souza e Ferreira (2017).

24 É importante registrar que o sistema e-MEC mantém em seu banco de dados as seguintes categorizações quanto à situação do curso e/ou IES: em atividade, em extinção, extinto, sub-judice. Na busca realizada para a produção desse trabalho, levantamos somente os cursos em atividade. Assim, trabalhos anteriores podem ter identificado cursos que não estão contemplados atualmente, provavelmente porque foram extintos.

25 Alguns estudos que analisam os novos cursos públicos criados no período vêm sendo produzidos no âmbito dos Programas de Pós-Graduação em Serviço Social. Cf. a tese de doutorado de Gonçalves (2013), sobre o curso de Serviço Social da Universidade Federal de Goiás (UFG); Villar (2015), sobre os cursos públicos de Serviço Social implantados no Rio Grande do Sul; Coral (2016), tese de doutorado sobre o curso de Serviço Social da Universidade Federal de Alagoas (UFAL) em Palmeira dos Índios; e Vitorino (2016), dissertação de mestrado, que trata do curso de Serviço Social na Universidade Federal do Triângulo Mineiro (UFTM). Lima (2013) analisou a expansão de vagas discentes ofertadas nos cursos de Serviço Social das universidades federais. Contudo, não encontramos estudos mais gerais, que abordassem o conjunto dos novos cursos públicos de Serviço Social criados no período em análise. Assim, esse é um tema que ainda carece de pesquisas.

26 Cursos públicos de Serviço Social criados no período em análise, nas seguintes IES (região nordeste): Universidade Federal de Alagoas (UFAL) em Palmeira dos Índios/Alagoas; Universidade Federal da Bahia (UFBA) em Salvador/Bahia; Universidade Federal do Recôncavo da Bahia (UFRB) em Cachoeira/Bahia; Instituto Federal de Educação, Ciência e Tecnologia do Ceará (IFCE) em Iguatu/Ceará; Universidade Federal de Campina Grande (UFCG) em Sousa/Paraíba; e Faculdade de Ciências Humanas e Sociais de Serra Talhada (FACHUSST) em Serra Talhada/ Pernambuco.

27 Cursos públicos de Serviço Social criados no período em análise, nas seguintes IES (região norte): Universidade Federal de Amazonas (UFAM) em Parintins/Amazonas; Universidade Federal do Pará (UFPA) em Breves/Pará; Fundação Universidade Federal de Tocantins (UFT) em Miracema/Tocantins; Universidade Estadual de Roraima (UERR) em Boa Vista/Roraima; Universidade do Tocantins (UNITINS) em Palmas/ Tocantins.

28 Curso público de Serviço Social criado no período em análise, região norte: Universidade Federal de Goiás (UFG), em Goiás/Goiânia.

29 Cursos públicos de Serviço Social criados no período em análise, no estado do Rio de Janeiro: Universidade Federal Fluminense (UFF), em Rio das Ostras; Universidade Federal do Estado do Rio de Janeiro (UNIRIO), no Rio de Janeiro; e Universidade Federal Rural do Rio De Janeiro (UFRRJ), em Seropédica.

30 Cursos públicos de Serviço Social criados no período em análise, no estado de São Paulo: Universidade Federal de São Paulo (UNIFESP) em Santos, e Faculdade de Ciências e Letras de Bragança Paulista(FESB) em Bragança Paulista.

31 Cursos públicos de Serviço Social criados no período em análise, no estado de Minas Gerais: Universidade do Estado de Minas Gerais (UEMG), nos municípios de Abaeté, Carangola, Cláudio e Divinópolis; Universidade Estadual de Montes Claros (UNIMONTES) em Montes Claros; Universidade Federal de Ouro Preto (UFOP) em Mariana; Universidade Federal de Uberlândia (UFU) em Ituiutaba; Universidade Federal dos Vales do Jequitinhonha e Mucuri(UFVJM) em Teófilo Otoni; Universidade Federal do Triângulo Mineiro (UFTM) em Uberaba; e Universidade Federal de Viçosa (UFV) em Viçosa.

32 Cursos públicos de Serviço Social criados no período em análise, região sul: Universidade Federal do Paraná (UFPR) em Matinhos/Paraná; Universidade Federal da Integração Latino-Americana(UNILA) em Foz do Iguaçu/Paraná; Universidade Estadual do Oeste do Paraná (UNIOESTE), em Cascavel/Paraná; Universidade Estadual de Maringá (UEM), em Ivaiporã/Paraná; Fundação Universidade Federal do Pampa (UNIPAMPA) em São Borja/Rio Grande do Sul; Universidade Federal do Rio Grande do Sul (UFRGS) em Porto Alegre/Rio Grande do Sul; e Universidade Federal de Santa Maria (UFSM) em Santa Maria/Rio Grande do Sul.

33 A professora Adriana Freire Pereira Férriz vem desenvolvendo pesquisa sobre a abertura do curso de Serviço Social da UFBA. Cf. FÉRRIZ et al. (2017). 


\section{Larissa Dahmer Pereira}

larissadahmer@hotmail.com

Doutorado em Serviço Social pela Universidade Federal do Rio de Janeiro (UFRJ)

Professora Associada II da Universidade Federal Fluminense (UFF)

\section{UFF}

Rua Professor Marcos Waldemar de Freitas Reis, s/n $/ n^{\circ}$ Bloco E

Campus do Gragoatá - São Domingos

Niterói - Rio de Janeiro - Brasil

CEP: 24.210-201 